\title{
Agribisnis Perkebunan di Kabupaten Cilacap Provinsi Jawa Tengah
}

\section{Agribusiness of Plantation Crops in Cilacap Regency Central Java Province}

\author{
Agus Dwi Nugroho*1, Mais Ilsan ${ }^{2}$, Efrinda $^{3}$, Winaryo ${ }^{4}$, Rini Handoyo ${ }^{5}$, \\ Suparmono $^{6}$, Reineta Puspitasari ${ }^{4}$ \\ ${ }^{1}$ Departemen Sosial Ekonomi Pertanian Fakultas Pertanian Universitas Gadjah Mada, Jl. Flora \\ Bulaksumur Yogyakarta 55281 \\ ${ }^{2}$ Fakultas Pertanian Universitas Muslim Indonesia \\ ${ }^{3}$ Sekolah Vokasi Universitas Gadjah Mada \\ ${ }^{4}$ Fakultas Geografi Universitas Gadjah Mada \\ ${ }^{5}$ Fakultas Teknik Geologi Universitas Padjajaran \\ ${ }^{6}$ Fakultas Ekonomika dan Bisnis Universitas Gadjah Mada \\ *E-mail : agusdwinugroho@yahoo.com
}

\begin{abstract}
Plantation is considered strategic in Cilacap, but now the condition of farmers are marginalized. Therefore, it is necessary to do research to find out the main plantation crops in Cilacap and the strategy to development. This research was conducted in June-August 2016. The data used is primary data through observations, interviews farmer and agricultural bureau. The secondary data collected from the relevant agencies. Analysis of data using Location Quotient, Rasmussen's Dual Criterion and SWOT. The main commodities for plantation crops are coconut, rubber and nutmeg. In order to develop agribusiness need improving the human resources quality; increasing promotional and information efforts of main commodities for investors; extending the land, controlling over land use, guaranting prices of commodities, climate change mitigation, infrastructure development and credit accessibility for farmers.
\end{abstract}

Keywords : agribusiness, location quotient, rasmussen's dual criterion, SWOT

Disubmit : 13 September 2017, Diterima : 01 Desember 2017, Disetujui :08 Desember 2017

\section{PENDAHULUAN}

Kabupaten Cilacap sebagai salah satu wilayah dengan bentang alam yang bervariasi memiliki potensi untuk pengembangan berbagai komoditas perkebunan. Tetapi pada kenyataannya kondisi petani di daerah tersebut semakin termarginalkan. Hal tersebut dikarenakan sub sektor perkebunan beserta tanaman bahan pangan, peternakan dan perikanan merupakan sektor non basis dalam pembangunan wilayah di kabupaten Cilacap sedangkan yang menjadi basis yaitu sub sektor kehutanan (Ropingi dkk, 2009). Sehingga untuk meningkatkan kondisi petani di kabupaten Cilacap perlu dilakukan peningkatan kondisi sector perkebunan agar menjadi basis pembangunan. Oleh karena itu, perlu dilakukan kegiatan penelitian untuk mengetahui komoditas unggulan perkebunan di Kabupaten Cilacap dan strategi pengembangan komoditas tersebut. 


\section{METODE PENELITIAN}

Penelitian ini dilaksanakan pada bulan Juni-Agustus 2016. Jenis data yang digunakan adalah data primer melalui observasi lapangan dan wawancara petani dan pemerintah serta data sekunder seperti RTRW, RPJMD, profil wilayah dan hasil kajian sebelumnya mengenai agribisnis di Cilacap.Data yang diperoleh kemudian dianalisis dengan : Analisis Location Quotient (LQ) untuk menentukan komoditas unggulan (Alhowaish, et.al, 2015).

$$
\mathrm{LQ}=\frac{(X i c / X i .)}{(X i j / X i . .)}
$$

Keterangan :

LQ $\quad=$ indeks kuosien lokasi komoditi i di Kabupaten Cilacap

Xic = luas lahan komoditas perkebunan i di Kabupaten Cilacap

Xi. $\quad=$ luas lahan komoditas perkebunan di Kabupaten Cilacap

$\mathrm{Xij} \quad=$ luas lahan komoditas perkebunan i di Provinsi Jawa Tengah

Xi.. $\quad=$ luas lahan komoditas perkebunan di Provinsi Jawa Tengah

Hasil perhitungan LQ menghasilkan tiga (3) kriteria yaitu : 1) LQ > 1 artinya, komoditas itu menjadi basis atau menjadi sumber pertumbuhan; 2) LQ $=1$ artinya, komoditas itu tergolong non basis, tidak memiliki keunggulan komparatif; dan 3) LQ $<1$ artinya, komoditas ini juga termasuk non basis. Dari hasil analisis LQ ini akan dipilih 3 komoditas unggulan serta disesuaikan dengan hasil kajian sebelumnya mengenai agribisnis dan kebijakan pemerintah pusat maupun daerah.

Rasmussen's dual criterion untuk mengetahui keunggulan komparatif terhadap produk yang merupakan basis pengembangan dari hasil perhitungan LQ. Analisis Rasmussen's dual criterion (RDC) terdiri dari 10 kriteria yaitu ketersediaan SDA, ketersediaan sumberdaya buatan, ketersediaan SDM, kontribusi terhadap perekonomian kawasan, kemungkinan dikembangkan dalam skala ekonomi/industri, mampu menyerap tenaga kerja, berdampak pada pengembangan spasial, potensi pasar lokal, potensi pasar ekspor dan hambatan biaya, teknologi dan kelembagaan. Kesepuluh komponen RDC tersebut akan dilakukan pembobotan untuk setiap komoditas yang merupakan basis pengembangan di wilayah dengan tiga tingkatan yaitu 1) Baik dengan skor 3; 2) Sedang dengan skor 2; dan 3) Buruk dengan skor 1. Hasil pembobotan dari 10 kriteria RDC akan didefenisikan dalam tiga tingkatan yaitu 1) Unggul jika nilai skor berada pada kisaran 24 sampai 30; 2) Pengembangan jika skor berada pada kisaran 17 sampai 23; dan 3) Kurang Unggul jika skor berada pada kisaran 10 sampai 16 (Tajerin, dkk, 2010).

Analisis SWOT yang digunakan untuk mengidentifikasi dan memprioritaskan tujuan bisnis serta strategi untuk mencapainya dengan melihat Strengths, Weaknesses, Opportunities, Threats suatu bisnis (Ommani, 2011).

\section{HASIL DAN PEMBAHASAN}

Analisis Keunggulan Komparatif. Wilayah Cilacap memiliki topografi yang bervariasi sehingga cocok untuk pertumbuhan tanaman perkebunan. Komoditas perkebunan basis yang terdapat di Cilacap antara lain aren, cengkeh, kakao, kelapa dalam, kopi robusta, lada, nilam, pala, sereh wangi, dan tembakau rajungan. Beberapa wilayah yang cocok untuk tanaman perkebunan adalah Majenang dan Dayeuluhur serta wilayah lainnya. Berdasarkan hasil analisis LQ, nilai tertinggi adalah komoditas perkebunan komoditas sereh wangi (Gambar 1). Namun, penyebaran komoditas sereh wangi hanya berada di Kecamatan Dayeuhluhur dan Kecamatan Wanareja (Tabel 1). 


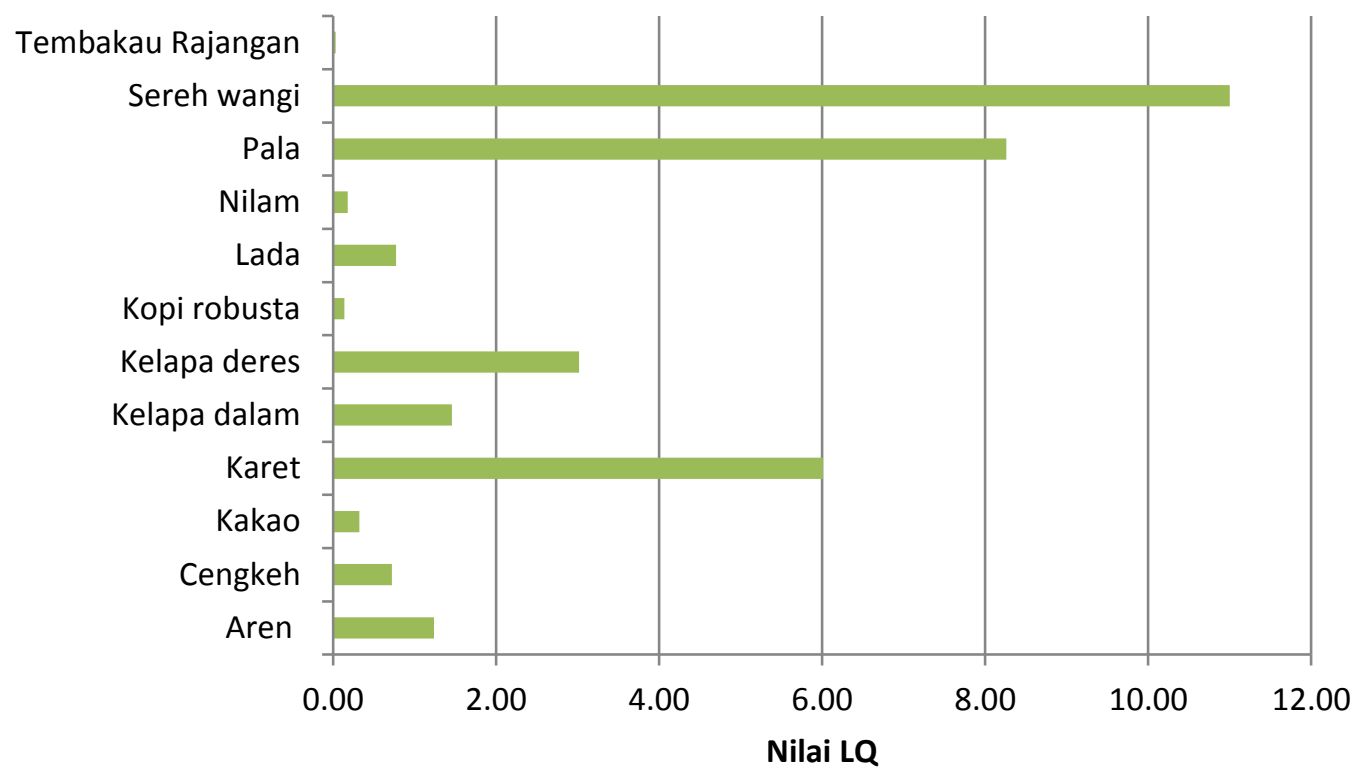

Gambar 1. Hasil Analisis LQ Subsektor Tanaman Perkebunan Kabupaten Cilacap

Dengan melihat data analisis LQ dan persebaran yang ada maka komoditas unggulan perkebunan di Cilacap adalah kelapa deres, karet dan pala.

Analisis Rasmussen's dual. Usaha yang cukup dikenal di Cilacap adalah pembuatan gula semut. Bahan baku gula semut dari tanaman kelapa deres. Pembuatan gula semut selama ini dilaksanakan dalam skala industri rumah tangga dengan tenaga kerja dalam keluarga. Perkembangan usaha ini membuat petani bersedia untuk menyewa pohon kelapa deres menyebabkan peningkatan biaya produksi.

Tabel 1. Lokasi Pengembangan Subsektor Tanaman Perkebunan Kabupaten Cilacap

\begin{tabular}{ll}
\hline Komoditas & Lokasi Utama Pengembangan \\
\hline Aren & Dayeuluhur \\
Cengkeh & Majenang dan Wanareja \\
Kakao & Karangpucung \\
Karet & Dayeuluhur dan Majenang \\
Kelapa dalam & Majenang, Patimuan, Nusawungu, Gandrungmangu dan Dayeuluhur \\
Kelapa deres & Jeruklegi, Gandrungmangu, Kroya, Nusawungu, Kawunganten dan Patimuan \\
Kopi robusta & Dayeluhur dan Majenang \\
Lada & Karangpucung, Cimanggu dan Majenang \\
Nilam & Majenang \\
Pala & Cimanggu dan Dayeluhur \\
Sereh wangi & Wanareja dan Dayeuluhur \\
Tembakau Rajangan & Sampang dan Kroya \\
\hline
\end{tabular}

Sumber : Kabupaten Cilacap Dalam Angka (2015)

Nilai RDC kelapa deres memiliki skor 28 berarti pada kategori unggul. Pengembangan kelapa deres termasuk komoditas yang memiliki potensi sangat baik sehingga dapat menjadi komoditas ekspor, meningkatkan penyerapan tenaga kerja dan berkontribusi terhadap perekonomian seperti di Kecamatan Batuda dan Kecamatan Bongomeme (Kabupaten Gorontalo) sehingga kontribusi pendapatan yang diperoleh dari usahatani kelapa lebih tinggi apabila dibandingkan pendapatan dari sumber lainnya (Bahua, 2014). 
Untuk itu pengembangan agroindustri kelapa deres membutuhkan investasi yang besar sehingga pemerintah perlu mengambil kebijakan membuka peluang investasi pembangunan agroindustri kelapa.

Komoditas perkebunan selanjutnya yang menjadi komoditas basis adalah karet, terutama di Cilacap Utara. Usaha perkebunan karet memberikan pemasukan cukup besar bagi rumah tangga dan pemerintah. Upaya pengembangan tanaman karet telah dilakukan Pemprov Jawa Tengah dengan memberikan pelatihan teknik menyadap karet sehingga produksi optimal serta dapat meningkatkan kualitas sadapan. Pemkab Cilacap juga turut serta dalam pengembangan komoditas karet dengan memberikan bantuan bibit dan permodalan. Masalah permodalan ini menjadi sangat penting untuk pengembangan usaha. Kasus di Sumatera Barat menunjukkan bahwa program pengembangan modal usaha KUPS ternyata mampu meningkatkan kinerja usaha kelompok peternak sapi. Keberhasilan tersebut tidak lepas dari usaha bersama antara pihak bank, Dinas Peternakan dan Kesehatan Hewan dan Kelompok peternak untuk secara bersama-sama berusaha secara sinergi menuju keberhasilan program (Winarso, 2015).

Pemasaran produk karet tidak mengalami banyak masalah karena akan ditampung PTPN IX. Namun pada kenyataannya, petani juga masih mengalami masalah harga jual karet yang berfluktuasi tergantung pada harga karet internasional. Harga jual karet di Kabupaten Paser juga tidak stabil karena mengikuti harga pasar karet dunia (Permatasari, 2016). Pemerintah Kabupaten Paser sendiri pun sampai saat ini tidak bisa mengambil tindakan dalam mempertimbangkan dan menetapkan harga jual yang relatif tinggi sehingga pemerintah perlu berinisiatif memikirkan agar harga karet tetap stabil dengan harga jual tinggi agar masyarakatnya sejahtera. Masalah lain perkebunan karet di Cilacap adalah belum adanya peremajaan tanaman karet sehingga terjadi penurunan produktivitas tanaman.

RDC karet di Kabupaten Cilacap sebesar 27 berarti komoditas tersebut berada pada kategori unggul. Namun demikian masih diperlukan perbaikan pada beberapa komponen dari analisis keunggulan komparatif misalnya kontribusi terhadap perekonomian wilayah masih rendah, tetapi hal ini bisa ditingkatkan jika animo petani karet dirangsang untuk mengelola karet dengan baik serta peningkatan pembukaan lahan yang potensial untuk ditanami karet oleh pihak investor. Kebijakan ini sangat mendukung konsep peningkatan investasi agribisnis. Jika hal ini tercapai maka penyerapan tenaga kerja pada sektor ini akan meningkat, sehingga tingkat kesejahteraan petani karet dapat meningkat.

Kabupaten Cilacap selain mengembangkan kelapa deres dan karet juga mengembangkan pala sebagai salah satu komoditas perkebunan. Hasil analisis LQ menunjukkan pala termasuk komoditas basis pengembangan. Hasil analisis RDC menunjukkan bahwa komoditas pala di Kabupaten Cilacap unggul karena nilai skor RDC sebesar 24. Berdasarkan skor dari 10 kriteria keunggulan komparartif menunjukkan bahwa ketersediaan sumberdaya buatan yang mendukung pengembangan tanaman pala membuat komoditas tersebut layak untuk dikembangkan dalam skala ekonomi (Tabel 2).

Dalam rangka pengembangan komoditas unggulan, Kabupaten Cilacap perlu melakukan berbagai strategi (Tabel 3). Pengembangan perkebunan sangat memerlukan kemitraan dengan investor karena (1) tuntutan masyarakat tentang redistribusi peluang usaha, aset produksi dan manfaat kepada petani, dan (2) tantangan global dalam melakukan usaha perkebunan yakni menguasai pasar input produksi untuk meringankan biaya produksi dan menguasai industri hilir yang memiliki marjin keuntungan terbesar (Fadjar, 2006). Selain dengan investor, Pemkab Cilacap perlu untuk memikirkan pola agroforestri dalam rangka meningkatkan produksi perkebunan. Hasil penelitian Thamiem, et al (2011) mengungkapkan bahwa meskipun dilaksanakan secara tradisional, namun tanaman perkebunan memiliki nilai kompetitif yang tinggi dibandingkan sistem non-tradisional. Tanaman tersebut juga memiliki daya saing di pasar dunia. Studi ini merekomendasikan pelaksanaan agroforestry yang merupakan kerja sama antara petani dengan instansi pemerintah untuk perluasan areal tanam. 
Nugroho dkk :Agribisnis Perkebunan di Kabupaten Cilacap Provinsi Jawa Tengah

Tabel 2. Analisis Rasmussen's Dual Criterion (RDC) Perkebunan di Kabupaten Cilacap

\begin{tabular}{|c|c|c|c|c|c|c|c|}
\hline No & Kriteria & Kelapa Deres & Skor & Karet & Skor & Pala & Skor \\
\hline 1 & $\begin{array}{l}\text { Ketersediaan sumberdaya } \\
\text { alam }\end{array}$ & $\begin{array}{l}\text { Beberapa lokasi memiliki banyak } \\
\text { pohon kelapa deres serta kemudahan } \\
\text { transportasi }\end{array}$ & 3 & $\begin{array}{l}\text { Ketersediaan lahan cukup bagus } \\
\text { dan luas }\end{array}$ & 3 & $\begin{array}{l}\text { Lahan telah tersedia, bantuan benih } \\
\text { pemerintah, masih dibutuhkan } \\
\text { pengairan }\end{array}$ & 3 \\
\hline 2 & $\begin{array}{l}\text { Ketersediaan sumberdaya } \\
\text { buatan }\end{array}$ & $\begin{array}{l}\text { sarana produksi tersedia dan mudah } \\
\text { dijangkau }\end{array}$ & 3 & Ketersediaan pupuk bagus & 3 & $\begin{array}{l}\text { Perlu dikembangkan jaringan } \\
\text { irigasi }\end{array}$ & 2 \\
\hline 3 & $\begin{array}{l}\text { Ketersediaan sumbedaya } \\
\text { manusia }\end{array}$ & $\begin{array}{l}\text { Tenaga kerja terbatas pada anggota } \\
\text { keluarga. }\end{array}$ & 2 & $\begin{array}{l}\text { Ketersediaan tenaga kerja bagus, } \\
\text { tetapi petani terkadang tidak } \\
\text { mampu membayar gaji }\end{array}$ & 3 & $\begin{array}{l}\text { Sumber daya manusia cukup } \\
\text { memenuhi }\end{array}$ & 3 \\
\hline 4 & $\begin{array}{l}\text { Kontribusi terhadap } \\
\text { perekonomian }\end{array}$ & $\begin{array}{l}\text { Sudah cukup berpengaruh sebab } \\
\text { sebagian besar warga menderes } \\
\text { kelapa dan memproduksi gula }\end{array}$ & 3 & $\begin{array}{l}\text { Kontribusi dalam perekonomian } \\
\text { rendah karena harga karet rendah } \\
\text { namun apabila harga naik maka } \\
\text { kontribusinya tinggi }\end{array}$ & 2 & $\begin{array}{l}\text { Perkebunan pala masih dalam skala } \\
\text { kecil }\end{array}$ & 2 \\
\hline 5 & $\begin{array}{l}\text { Kemungkinan } \\
\text { dikembangkan skala } \\
\text { ekonomi/industri }\end{array}$ & $\begin{array}{l}\text { Potensial dikembangkan ke skala } \\
\text { lebih besar sebab area tanam pohon } \\
\text { masih luas }\end{array}$ & 3 & $\begin{array}{l}\text { Mampu dibangun sebuah pabrik } \\
\text { industri hasil karet } \\
\text { ban dll) }\end{array}$ & 3 & $\begin{array}{l}\text { Kemungkinan sangat besar karena } \\
\text { kebutuhan olahan pala sangat besar }\end{array}$ & 2 \\
\hline 6 & $\begin{array}{l}\text { Mampu menyerap tenaga } \\
\text { kerja }\end{array}$ & $\begin{array}{l}\text { Daya serap tenaga kerja sedikit tetapi } \\
\text { akan meningkat tergantung skala } \\
\text { usaha }\end{array}$ & 2 & $\begin{array}{l}\text { Tenaga muda banyak yang pergi } \\
\text { ke kota sehingga membutuhkan } \\
\text { banyak tenaga kerja }\end{array}$ & 2 & $\begin{array}{l}\text { Tenaga kerja dari lingkungan } \\
\text { sekitarnya }\end{array}$ & 3 \\
\hline 7 & $\begin{array}{l}\text { Berdampak pada } \\
\text { pengembangan spasial }\end{array}$ & merupakan sentra produksi gula & 3 & Skala usaha total sangat besar & 3 & Sangat potensial apabila skala besar & 2 \\
\hline 8 & Potensi pasar lokal & $\begin{array}{l}\text { Prospektif sebab kebutuhan di } \\
\text { Cilacap tinggi. }\end{array}$ & 3 & Potensi pasar lokal sangat baik & 3 & $\begin{array}{l}\text { Hasil lebih banyak dipasarkan di } \\
\text { Cilacap }\end{array}$ & 3 \\
\hline 9 & $\begin{array}{l}\text { Potensi pasar ekspor ke } \\
\text { luar daerah }\end{array}$ & $\begin{array}{l}\text { Sangat prospektif sebab gula adalah } \\
\text { kebutuhan mendasar rumah tangga. }\end{array}$ & 3 & $\begin{array}{l}\text { Ada potensi ekspor karena } \\
\text { kualitas getah karet bagus }\end{array}$ & 3 & $\begin{array}{l}\text { Sangat besar karena kebutuhan } \\
\text { olahan pala cukup besar }\end{array}$ & 2 \\
\hline 10 & $\begin{array}{l}\text { Hambatan biaya, teknologi } \\
\text { dan kelembagaan }\end{array}$ & $\begin{array}{l}\text { Kelembagaan cukup solid tetapi } \\
\text { mayoritas penderes masih menyewa } \\
\text { pohon sehingga biaya produksi naik. } \\
\text { Ketersediaan alat juga masih terbatas } \\
\text { dan terjadi fluktuasi harga serta } \\
\text { petani masih sering mengabaikan } \\
\text { standar mutu }\end{array}$ & 3 & $\begin{array}{l}\text { Pembiayaan saat ini sangat } \\
\text { kurang bagus karena harga getah } \\
\text { karet sedang rendah. Teknologi } \\
\text { kurang bagus karena petani } \\
\text { bertani secara tradisional.dan } \\
\text { petani masih sering mengabaikan } \\
\text { standar mutu }\end{array}$ & 2 & $\begin{array}{l}\text { Harga semakin menurun, sehingga } \\
\text { penanaman pala semakin } \\
\text { berkurang, serangan organisme } \\
\text { pengganggu tanaman dan bunga } \\
\text { pala yang terkena angin kencang } \\
\text { menurunkan produktivitas }\end{array}$ & 2 \\
\hline & $\begin{array}{l}\text { Total Skor } \\
\text { Kriteria }\end{array}$ & & $\begin{array}{c}28 \\
\text { Unggul }\end{array}$ & & $\begin{array}{c}27 \\
\text { Unggul }\end{array}$ & & $\begin{array}{c}24 \\
\text { Unggul }\end{array}$ \\
\hline
\end{tabular}




\begin{tabular}{|c|c|c|}
\hline & Kekuatan & Kelemahan \\
\hline EKSTERNAL FAKTOR & $\begin{array}{l}\text { 1. UU memberikan berbagai kewenangan kepada } \\
\text { pemerintah kabupaten } \\
\text { 2. Tanaman perkebunan menjadi salah satu fokus } \\
\text { pembangunan ekonomi } \\
\text { 3. Perda yang menerapkan pola maksimal dengan } \\
\text { membentuk dinas teknis pertanian } \\
\text { 4. Tersedianya pembiayaan pembangunan daerah dari } \\
\text { DAU, DAK, APBD Provinsi dan Tugas Pembantuan } \\
\text { (APBN); } \\
\text { 5. Potensi sumberdaya alam serta ketersediaan lahan } \\
\text { yang besar } \\
\text { 6. Sumber Daya Aparatur/Penyuluh dan petani cukup } \\
\text { banyak } \\
\text { 7. Dukungan pemerintah daerah dalam bentuk } \\
\text { penyuluhan, pelatihan, studi banding dsb } \\
\text { 8. Letak strategis sehingga mendukung dalam } \\
\text { pengembangan kegiatan ekonomi }\end{array}$ & $\begin{array}{l}\text { 1. Topografi daerah bergunung dan berlembah yang } \\
\text { sebagian masih ditumbuhi hutan menjadi kendala } \\
\text { dibukanya jalan darat yang menuju daerah-daerah } \\
\text { pedesaan secara cepat. } \\
\text { 2. Teknologi produksi dan pengolahan hasil masih } \\
\text { kurang sehingga kualitas produk masih rendah } \\
\text { 3. Modal petani yang terbatas sehingga produksi } \\
\text { belum optimal } \\
\text { 4. Kualitas SDM serta kelembagaan pertanian masih } \\
\text { terbatas } \\
\text { 5. Akses kredit dari perbankan masih enggan untuk } \\
\text { membantu pengembangan usaha } \\
\text { 6. Alih fungsi lahan meningkat } \\
\text { 7. Sistem pemasaran belum efisien } \\
\text { 8. Infrastruktur pertanian masih perlu ditingkatkan }\end{array}$ \\
\hline
\end{tabular}

\section{Peluang}

1. Daya dukung lahan masih cukup terbuka dan dapat dioptimalkan produktivitasnya

2. Kemajuan inovasi bahan pendukung pertanian di dunia

3. Pertumbuhan penduduk masih relatif tinggi

4. Kabupaten Cilacap yang dikenal sebagai penghasil perkebunan yang cukup besar

5. Kesempatan untuk penanaman modal di sektor pertanian masih terbuka lebar,

6. Tersedianya kredit usaha tani ; a. Pengembangkan komoditas berorientasi pasar dan fasilitas sarana-prasarana pendukungnya dengan memanfaatkan sumber pembiayaan yang tersedia

b. Optimalisasi peranan stakeholders dalam mengembangkan mutu hasil, distribusi dan, promosi produk unggulan serta meningkatkan pemberdayaan kelembagaan pertanian

c. Optimalisasi produksi melalui penyediaan benih unggul, pupuk, dan pestisida secara lokal dan kontinu melalui kerja sama dengan pedagang / penangkar a. Pengembangan komoditas secara terpadu

b. Penguatan kualitas SKPD dan petani melalui penyuluhan, pelatihan, diklat, magang, studi banding dsb baik di subsistem budidaya maupun olahan hasil dan pemasaran

c. Mendorong investasi usaha yang membantu permodalan, penyediaan sarana produksi, olahan hasil serta infrastruktur pendukung

d. Kebijakan pengendalian alih fungsi lahan

e. Penyediaan skema kredit yang mudah diakses oleh

Hal 162 Volume 17, Nomor 3, Tahun 2017 
Nugroho dkk :Agribisnis Perkebunan di Kabupaten Cilacap Provinsi Jawa Tengah

7. Tersedianya pedagang / penangkar benih tanaman perkebunan untuk memenuhi kebutuhan benih unggul

8. Multiplier effect akibat adanya berbagai aktivitas ekonomi akan merangsang pertumbuhan pembangunan termasuk pembangunan pertanian

\section{Ancaman}

1. Belum optimalnya koordinasi antar SKPD yang menangani pengembangan agribisnis

2. Posisi geografis Cilacap memungkinkan masuknya produk pertanian dari luar

3. Potensi tidak merata antar kecamatan sehingga kebijakan tidak dapat terintegrasi

4. Produksi dan kemajuan industri perkebunan negara ASEAN yang semakin tinggi,

5. Peningkatan serangan organisme pengganggu tanaman (OPT)

6. Fluktuasi harga akibat ketergantungan produksi pada iklim dan musim panen

7. Pertumbuhan sektor lain yang cepat mendorong alih fungsi lahan benih melalui pemanfaatan kredit yang tersedia

d. Penyediaan data dan informasi produk pertanian kepada investor

e. Mengembangkan produk organik

Strategi S-T

a. Pemerintah Kabupaten Cilacap menentukan arah koordinasi SKPD yang menangani produk unggulan daerah, pengembangan produk olahan hasil pertanian, dan optimalisasi pemasaran.

b. Membuka lahan pertanian baru di kecamatan yang memiliki tingkat kesuburan tanah yang mendukung untuk meningkatkan produktivitas pertanian

c. Mitigasi perubahan iklim untuk mengurangi dampak serangan OPT dan bencana

d. Mendorong olahan hasil untuk menjaga stabilitas harga produk petani, pendampingan usaha (pembukuan usaha, perijinan, dan pemasaran).

f. Menguatkan pola kebersamaan di tingkat petani untuk mempermudah pangawasan dan pemberian bantuan serta pemasaran hasil pertanian

\section{Strategi W-T}

Melakukan riset pasar yang efektif dengan cara menggandeng perguruan tinggi maupun pihak yang berkompeten sehingga dapat menetapkan tujuan pemasaran produk pertanian yang potensial 


\section{KESIMPULAN DAN SARAN}

Komoditas unggulan di Kabupaten Cilacap untuk tanaman perkebunan adalah kelapa deres, karet dan pala. Kabupaten Cilacap memiliki kekuatan dan peluang untuk pengembangan komoditas unggulan namun juga perlu dirumuskan strategi untuk mengatasi kelemahan dan tantangan yang ada. Sehingga perlu dilakukan strategi pengembangan komoditas unggulan dengan cara meningkatkan kualitas SDM pertanian serta kegiatan kelompok, kebijakan ekstensifikasi, pengendalian alih fungsi lahan, jaminan harga komoditas unggulan, mitigasi perubahan iklim, pengembangan infrastruktur serta kemudahan akses kredit bagi petani. Kemudian, informasi komoditas unggulan perlu disediakan bagi investor untuk meningkatkan promosi komoditas unggulan.

\section{UCAPAN TERIMA KASIH}

Penulis mengucapkan terima kasih kepada Bappeda Kabupaten Cilacap yang telah memberi dukungan finansial terhadap pelaksanaan penelitian "Penyusunan Kajian Peluang Investasi Agrobisnis" sehingga dapat dipublikasikan dalam Jurnal Penelitian Pertanian Terapan.

\section{DAFTAR PUSTAKA}

Alhowaish, A.K, Alsharikh, M.A, Alasmail, M.A Alghamdi. 2015. Location quotient technique and economy analysis of regions: Tabuk Province of Saudi Arabia as a case study. International Journal of Science and Research (IJSR) 4 (12) : 1756 - 1761.

Bahua, M.I. 2014. Kontribusi pendapatan agribisnis kelapa pada pendapatan keluarga petani di Kabupaten Gorontalo. Agriekonomika 3 (2) : $133-141$.

BPS. 2016. Kabupaten Cilacap Dalam Angka 2015. Badan Pusat Statistik. BPS Kabupaten Cilacap.

Fadjar, U. 2006. Kemitraan usaha perkebunan perubahan struktur yang belum lengkap. Forum Penelitian Agro Ekonomi 24 (1) : 46-60.

Ommani, A.R. 2011. Strengths, weaknesses, opportunities and threats (SWOT) analysis for farming system businesses management: case of wheat farmers of Shadervan District, Shoushtar Township, iran. African Journal of Business Management 5(22) : 9448-9454.

Permatasari, M. 2016. Pengembangan perkebunan rakyat oleh pemerintah kabupaten dan dampaknya terhadap kesejahteraan ekonomi masyarakat dan lingkungan (studi kasus perkebunan karet di Desa Mendik Makmur dan perkebunan sawit di Desa Tajer Mulya). eJournal Ilmu Pemerintahan 4 (1) : 268-281.

Ropingi, Agustono dan Yuliani, T. 2009. Analisis identifikasi dan peranan sektor pertanian dalam pembangunan wilayah di kabupaten cilacap. Jurnal Ekonomi Pembangunan 10 (2) : 139 - 153.

Tajerin, Madiyanto, dan Sastrawidjaja. 2010. Dinamika keterkaitan sektor kelautan dan perikanan dalam perekonomian Indonesia, 1995-2005: Pendekatan Rasmussen's Dual Criterion. Jurnal Kebijakan dan Riset Sosek Kelautan dan Perikanan. 5 (1) : 97 - 112.

Thamiem, S., J. Weerahewa., D.K.N.G. Pushpakumara and V.P. Singh. 2011. Trade competitiveness of agroforestry crop sector in Sri Lanka. Tropical Agricultural Research 22 (4) : 338 - 347.

Winarso, B. 2015. Keberhasilan Pengembangan Ternak Sapi Potong Melalui Pola Pengembangan Modal Usaha (KUPS). Jurnal Penelitian Pertanian Terapan 15 (2) : 138-150. 